\title{
Leveraging triple helix and system intermediaries to enhance effectiveness of protected spaces and strategic niche management for transitioning to circular economy
}

\author{
Jack Barrie, Girma Zawdie and Elsa João \\ (University of Strathclyde, Glasgow, UK)
}

\begin{abstract}
The transition to circular economy has been heralded as a vision to overcome the challenges of rapid population growth, economic stagnation and environmental degradation. A promising policy tool for accelerating such a transition is Strategic Niche Management (SNM), the central tenet of which is the formation of 'protected spaces' to support the growth of sustainable innovation. Studies have demonstrated that current top-down policy approaches to governing protected spaces have led to the unintended consequences of network tensions, low quality learning processes and low innovation adoption rates outside protected spaces. This limits the impact of SNM as a transition tool. Through a detailed literature review, this paper looks into a novel devolved governance framework for protected spaces in the context of transition to circular economy. The framework addresses current limitations of SNM by acknowledging the synergistic relationship with the triple helix innovation system; and innovation intermediation. Transition to circular economy turns on the achievement of 'triple helix consensus' across 'protected spaces' to provide the requisite platform for sustained innovation and for the recurrent choice of knowledge and market systems that are consistent with the circular economy growth trajectory.
\end{abstract}

Key Words: Circular Economy, Triple Helix, Consensus Space, Protected Spaces, Strategic Niche Management, Innovation Intermediaries

\section{Introduction}

Since the beginning of the industrial revolution, society has experienced a period of exponential economic growth that has led to significant rises in living standards. However, the linear economic system that fuelled this growth, often referred to as the 'take, make, dispose' model, has also brought in train disastrous side effects that now pose an existential threat to humanity. These range from the risk of catastrophic climate change, decimation of natural resources, and economic stagnation to the destruction of natural ecosystems through pollution and unsustainable consumption and production trends. To put this into perspective, 80 per cent of earth's natural forest has disappeared and 75 per cent of global fisheries are fished at or beyond capacity (WWF 2015; Food and Agriculture Organization 2010). The challenge is therefore twofold. Developed nations need to significantly reduce their ecological footprint per capita whilst retaining high standards of living and developing nations need to increase their standard of living without increasing their ecological footprint per capita (WWF 2014). To realise this goal, the linear economic model must give way to a systems-based model which is restorative and regenerative and which is capable of decoupling economic and social growth from material 
consumption to fit within planetary boundaries. The most widely used terminology for such an economic system is the 'Circular Economy'.

The challenges associated with accelerating the transition to circular economy are varied and complex, ranging from an uneven playing field created by current institutions to resistance from powerful stakeholders with large interests in the status quo (Cossio et al. 2015; Ellen MacArthur Foundation 2015). The majority of these cannot be tackled independently, but require systemic change to the structure of the global economy. To achieve this, deeply embedded path dependencies or 'lock-ins' within current socio-technical regimes need to be overcome.

Socio-technical regimes evolve to address fundamental societal needs such as water, energy and food supply. They form through the co-evolutionary build-up and alignment of knowledge, resources, practices, infrastructure, values and norms (Rip \& Kemp 1998). It is due to this coevolutionary formation that technological lock-ins develop whereby well-established general purpose technologies, such as the car or electricity grid, become deeply intertwined with culture and lifestyles, business models, infrastructure, regulations, institutional practices and politics. A significant change in established technologies can therefore have wide reaching and potentially disruptive effects on society.

Markard et al. (2012) argue that incremental change to unsustainable regimes, such as a fossil fuel-dominated energy sector, is unlikely to lead to the step change required to realise a circular economy within an appropriate timescale. In line with this argument, this paper proposes that radical innovation arising outwith existing socio-technical regimes must be encouraged through the mechanism of strategic niche management (SNM).

There is general agreement within the transition literature that niche innovations play a vital role in transforming or destabilizing incumbent socio-technical regimes (Rip \& Kemp 1998; Geels 2002; Markard et al. 2012; Smith \& Raven 2012). However, drawing from evolutionary economics, it is also recognised that niche innovations require initial support and protection from competition against well-established technologies and the selection pressures of the open market. Rosenberg (1976; p.195) states that the majority of inventions are "relatively crude and inefficient at the date when they are first recognised as constituting a new invention. They are, of necessity, badly adapted to many of the ultimate uses to which they will eventually be put".

SNM emerged as strategy for governments to manage the process of transition to a different regime through the provision of support for the development of and popularisation of niche inventions and innovations (Kemp et al. 1998). Kemp et al. (1998; p.186) defined SNM as the "creation, development and controlled phase-out of protected spaces for the development and use of promising technologies by means of experimentation, with the aim of: (i) learning about the desirability of the new technology and; (ii) enhancing the further development and the rate of application of the new technology". Since its introduction, SNM has predominantly been used as analytical tool to identify the success factors of various niche experiments ranging from wind energy, biomass, fuel cells and hydrogen to photovoltaics (Verbong et al. 2008; Raven 2006; Mlecnik 2014).

However, SNM faces an operational gap since it has predominantly been used as an analytical tool rather than being prescriptively applied to on-going processes (Caniëls \& Romijn 2008; Smith \& Raven 2012; Schot \& Geels 2008). Numerous studies have highlighted that the lack of operational or governance framework for SNM has led to significant unintended consequences, such as poor learning processes, false expectations and low innovation adoption rates outside the niche (Verbong et al. 2008; de Wildt-Liesveld et al. 2015). 
Transition to a circular economy can be achieved through multiple protected spaces targeted for example, at key circular economy growth markets such as renewable energy, biorefinery, remanufacturing, sustainable mobility and the sharing economy, to co-evolve, paving the way for smooth transition within a governance framework that is capable of mitigating tensions and conflicts that are likely to arise in the transition process.

The remainder of this paper is structured as follows. Section 2 explores the significance, limitations and requirements of SNM as a framework for the governance of protected spaces through a detailed literature review. Section 3 discusses the leveraging effect of the triple helix system and innovation intermediation on SNM as a governance framework for transition to circular economy in industrially developed economies. Finally, Section 4 outlines how such a framework connects with the problematics of the transition to a circular economy with reference to the Scottish experience.

\section{Strategic Niche Management}

\subsection{Overview of Strategic Niche Management}

Strategic Niche Management (SNM) emerged in the early 1990s as an evolutionary policy tool to facilitate the growth of radical and sustainable technological niche innovations (Kemp et al. 1998). It is based on the rationale that if radical innovations were to destabilise unsustainable technology regimes, they would require initial protection from the competitive pressures of the market through the formation of protected spaces (Schot \& Geels 2008; Nill \& Kemp 2009; Verbong et al. 2008; Raven 2006).

As an analytical tool, SNM has enabled an in-depth understanding of the conditions for successful widespread adoption of niche innovations as well as the mechanisms required to protect such innovations in the nascent stages of development (Verbong et al. 2008; Ulmanen et al. 2009; Boon et al. 2014; Kemp et al. 1998; Verhees et al. 2015).

There is general agreement in the literature that the success of protected spaces is dependent on three processes: (i) shielding; (ii) nurturing; and (iii) empowering (Boon et al. 2014; Verhees et al. 2015). Shielding is largely an outward looking process aiming to protect niche innovations from market selection pressures. Shielding mechanisms occur in various forms, including financial support, rule exemptions, basic research funding or dedicated programs (Verhees et al. 2015). Nurturing and empowering are more internally focused. Nurturing cultivates the innovation network within the protected space and is achieved through developing social capital by fostering shared expectations, promoting shared learning and building the actor network (Schot \& Geels 2008). Nurturing is essential to the health of the protected space as effective learning is unlikely to occur naturally between heterogeneous actors (Hoogma et al., 2002). Empowering innovators within the protected space involves initiatives that either allow niche innovations to compete against incumbent technologies or alter selection environments in favour of the niche innovation (Smith \& Raven 2012).

The relationships between shielding, nurturing and empowering in protected spaces are considered to be iterative and co-dependent (Boon et al. 2014; Verhees et al. 2015). Initial protection, for instance, leads to early nurturing and hence provides the conditions for the development of an innovation. If the innovation shows promise, then stronger protection mechanisms can be introduced which further assist nurturing and empowerment and eventually institutionalisation of the innovation network. Once the network within the protected spaces builds enough momentum to compete on an equal basis against incumbent technologies, protection measures would be expected to give way to continuous knowledge exchange 
between policy makers and actors on the innovation network over the lifetime of the protected space (Verhees et al. 2015).

\subsection{The need for a devolved reflexive governance framework for SNM}

One of the underlying assumptions of SNM is that governments cannot effectively implement protection measures via a centralised policy approach (Rip, 2006). A protected space is expected to emerge out of a collective co-evolutionary steering process between a range of societal actors; it therefore requires a more networked form of governance as opposed to the traditional linear approach to innovation pursued by most governments.

However, such a co-evolutionary steering process is rarely apparent as the steering of "niche experiments is not straightforward and is often associated with difficulties" (de Wildt-Liesveld et al. 2015; p.155). Moreover, Nilsson et al. (2012; p.51) observe that the way in which "governance should be best organised to achieve both momentum and a sustainable direction is not well understood". Hence a gap exists between the governance of niche experiments in theory and in practice as demonstrated by panels (a) and (b) in Figure 1.

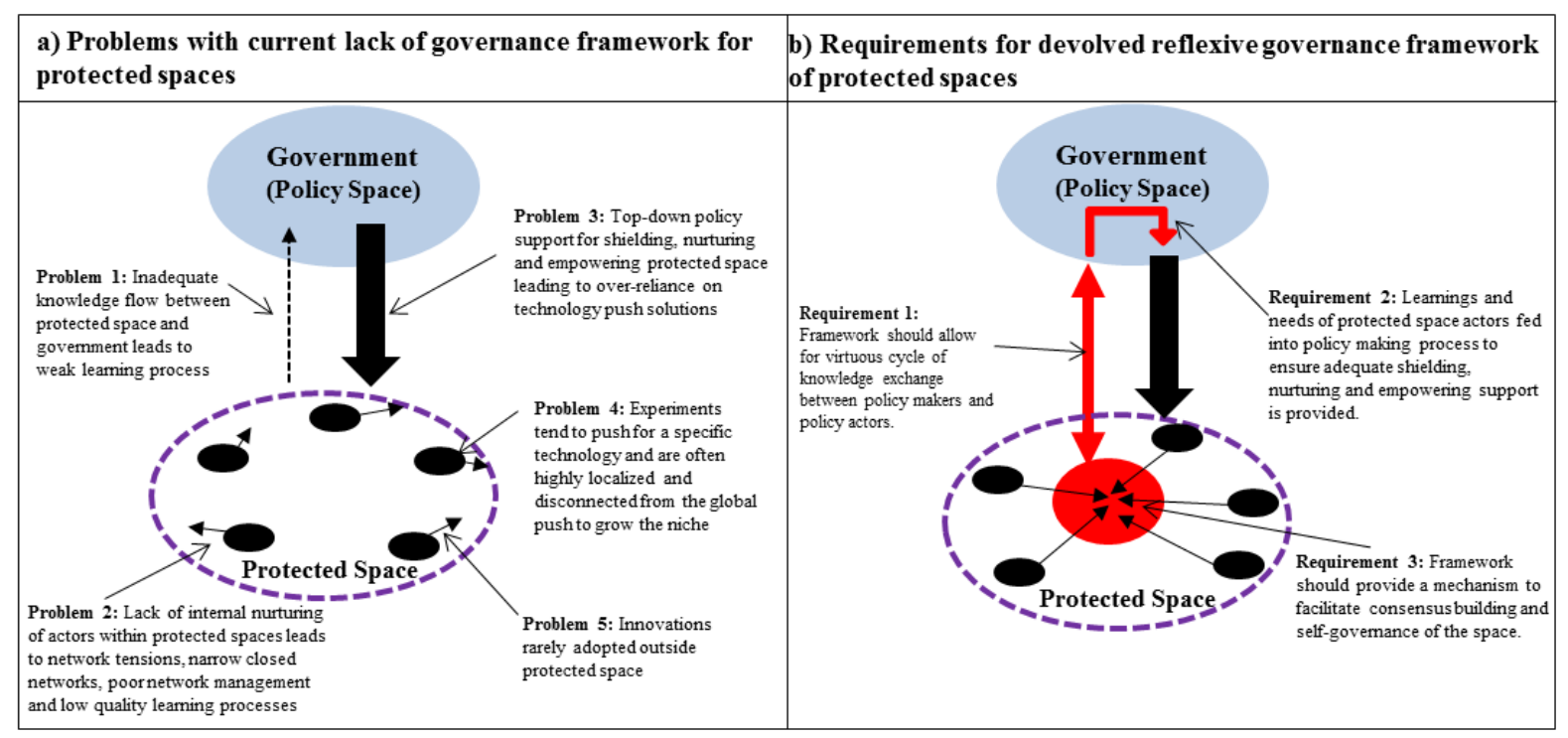

Figure 1: The need for a governance framework to facilitate reflexive governance of protected spaces and support the wider adoption of niche innovations

In the case of the energy sector in the Netherlands, from where the SNM concept originated, Verbong et al. (2008) demonstrated that the lack of niche management framework led to a 'muddled' linear top-down approach to innovation which produced unintended consequences such as poor learning processes, an over-reliance on technology push, narrow and closed social networks and false expectations (Figure 1- Problems 1, $2 \&$ 3). Schot \& Geels (2008) also show that, rather than the co-evolutionary dynamics that SNM advocates, experiments tend to push for a specific technology and are often highly localised and as such are disconnected from a broader push to grow a niche (Figure 1- Problems 4 \& 5).

The challenges associated with the governance of a single protected space become amplified when one considers the need for the existence of a systemic framework for the operation of multiple protected spaces to support transition to circular economy. The characteristics and dynamics of the governance challenges are likely to vary significantly across protected spaces targeted at the likes of renewable energy, industrial biotechnology, remanufacturing, 
sustainable mobility and the sharing economy. Thus, in the event of a policy attempt to promote transition to circular economy, the task of governance would become so complex that central government would be landed with the risk of information overload even to the point of paralysis. Moreover, the persistence of the interventionist approach would precipitate a bloating public sector, information overload, and hence the vicious circle of top-down management system.

In order to avoid information overload, a certain level of governance must be devolved to protected spaces. As Turnbull $(2002 ;$ p.41) argues, the delegation of power from government to a 'self-governing inclusive stakeholder network' may provide a stronger basis for the development of social capital, which Cooke \& Wills (1999) consider to be critical for the vitality of innovation networks. The need to increase self-governance is also alluded to by Schot \& Geels (2008; p.548) who posit that governance of a protected space "would require not only a change in the specific practice of organising experiments, but also broader institutional and cultural changes, particularly in the distribution of responsibilities and the organisation of relations between state, market, civil society and science and technology." Devolving the day to day governance of protected spaces would also minimise the amount of information that governments are required to absorb, and may also reduce the risk of information being lost, forgotten or distorted as it cascades down hierarchical and bureaucratic organisations.

Schot \& Geels (2008; p.550) recognise that niches are not the only forces that lead to technology regime changes. Niches, they argue, have to be developed in-line with the "ongoing processes at broader regime and landscape levels". This is particularly pertinent when one considers the need to steer multiple protected spaces in-line with a wider circular economy transition.

Schot \& Geels (2008; p.538) further suggest that although protected spaces require some level of self or 'endogenous' governance, there is still a role for external policy makers to play to ensure that the protected space is set on the trajectory of sustainability or circular economy by providing appropriate shielding, nurturing and empowering mechanisms that would enable the protected space to thrive. Smith (2004) also notes that top-down support is essential for a niche to evolve into mainstream. There is therefore the need for continuous knowledge exchange between the protected space network and policy makers to ensure the policy making process becomes more reflexive to the changing needs of the protected space (Figure 1 - Requirement $2 \& 3)$.

Reflexivity is increasingly being recognised as an important criteria for modern governance (Voß \& Kemp 2005). Reflexive governance is a response to globalisation creating an increasingly networked society. When systems thinking is combined with the notion of reflexivity, governance and policy evolve from singular points of intervention to a system of continual feedback in which further adjustments are made based on changing environmental conditions (Shove \& Walker 2007).

The analytical task of building reflexivity into the SNM process is not new (Schot \& Geels 2008). However, a study by Verbong et al. (2008) highlights that, in practice, SNM remains a government-led initiative of centralised policy approaches. This limits the ability of governments to adapt and align support mechanisms to shield, nurture and empower protected space networks, and to build the momentum for radical innovations needed for transition to circular economy (Figure 1 - Problems 1 \& 5). 
Raven (2005) discusses the need for a new governance framework for protected spaces that seeks to balance self-governance with top-down forms of governance. A degree of selfgovernance reduces the risk of information overload on policy makers as well as making the protected space networks more responsive to the changing market dynamics (Figure 1 Requirement 1). However, while government continue to play the critical roles of setting the protected space networks to evolve on a circular economy trajectory, and introducing policies to help shield, nurture and empower these protected space networks, it is important for the governance framework to promote reflexivity between policy makers and protected space network actors (Figure 1 - Requirement $2 \& 3$ ).

Thus, the protected space governance mechanism would provide the institutional structure for self-governance to evolve and for the niche to be managed on a day-to-day basis as championed by Weber et al. (1999) (Figure 1 - Requirement 3). However, the mechanism must also act as a vehicle for the transfer of learnings from the network to policy makers to allow for the introduction, alteration and eventual removal of shielding, nurturing and empowering polices as discussed in Raven (2005) and Ulmanen et al. (2009) (Figure 1 - Requirement 1 \& 2).

Although a devolved reflexive governance model for protected spaces appears more appropriate than the current interventionist model, the question remains as to how such a model may be effectively implemented, particularly with respect to the selection of technological trajectories that pave the way for transition to circular economy. The following section explores how the triple helix system and system intermediaries may enable the operationalization of a distributed reflexive governance model and leverage transition to circular economy.

\section{Triple Helix System and System Intermediaries}

Based on the acknowledgement of the current limitations of SNM, this section raises the idea of leveraging the symbiotic relationship between SNM and the two separate fields that attempt to address the challenge of accelerating radical innovation for sustainability: (i) the triple helix innovation system; and (ii) innovation intermediation. Each approach will be analysed with regard to their ability to allow for more effective distributed and reflexive governance of protected spaces through a critical analysis of the literature. A governance framework is then proposed and examined in the light of policy initiatives in Scotland for transition to circular economy.

\subsection{The Triple Helix System}

The triple helix concept was first introduced by Etzkowitz \& Leydesdorff (1995) with the recognition that to transition to a knowledge society, a hybridisation of university, government and industry would need to provide a systemic framework for the effective generation, diffusion and use of knowledge. This would require the blurring and overlapping of traditional government-university-industry boundaries (Etzkowitz 2011). The concept is increasingly embracing new forms of governance theory to enable this hybridization to occur, including evolutionary economics, network building, reflexivity and systems thinking (Etzkowitz \& Leydesdorff 2000; Farinha et al. 2014).

The application of the principles of the triple helix approach to the governance of protected spaces appears beneficial. By building an institutional overlap between government, academia and industry, the processes of knowledge generation and knowledge exchange are enhanced. This overlapping of roles between academia, government and industry supports the growth of social capital, increasing the chances of a shared vision developing between the protected space actors. The existence of social capital and a shared vision increases the feasibility of self- 
governance occurring (Cai 2015). The institutional overlaps create an interstitial space where innovation is more likely to occur. Furthermore, by offering government a more collaborative role within the network, a triple helix system would serve to enhance multi-level reflexivity between policy makers and policy implementers and hence strengthen a government's ability to introduce, adapt or remove shielding, nurturing and empowering policies. Perhaps more importantly, a triple helix system can be implemented at any level of the economy and society, thus opening the door for a more decentralised networked and evolutionary form of governance that would make protected spaces effective mechanisms for transition to circular economy.

Although the triple helix approach appears to offer a framework for enhancing the level of selfgovernance within protected spaces, Ranga \& Etzkowitz (2013) highlight that there remains a lack of understanding of what triggers the formation of a triple helix system. Also unsettled is the question of how a triple helix system may be prompted to form within a protected space and evolve into a 'consensus space', which, as will be discussed later, is crucial for the specification of pathways towards a circular economy.

Ranga and Etzkowitz (2013) conceptualise the formation and co-evolution of an ideal triple helix system in terms of the presence of a knowledge space, an innovation space a consensus space. The consensus space provides the forum for triple helix actors to brainstorm, debate and assess plans to advance towards a knowledge-based system through a number of co-created practices. It requires the build-up of social capital to engender trust and effective knowledge transfer. Government usually takes the lead role as a catalyst in the formation and management of the consensus space. The knowledge space forms through a range of activities that allow knowledge to be generated, diffused and used amongst the triple helix actors. Academia is often recognized to take the lead role in this space. The innovation space comprises of activities undertaken predominantly by hybrid organizations spanning the boundaries between the triple helix actors and is predominantly driven by industry (Ranga \& Etzkowitz. 2013).

The consensus space is considered critical for driving meaningful interaction between knowledge and innovation spaces. If there is limited consensus between the triple helix actors, hybrid organizations and transfer networks that make up the innovation space are unlikely to form and the full advantage afforded by the knowledge space is unlikely to be realised (Ranga \& Etzkowitz 2013). The consensus space provides the basis for the formation of the triple helix system. It can also be seen as the framework for 'selection environments' for projecting technological trajectories by drawing balance/consensus between stakeholders that account for knowledge generation and knowledge use and those who would regulate and control the direction and speed of these activities.

The formation of the consensus space, and indeed that of the triple helix system, is closely linked with the development of social capital which engenders trust among network players (Yokakul \& Zawdie 2009). Cai (2015) also argues that the formation and institutionalization of the triple helix system occur through regulative, normative and cognitive changes in the individual triple helix actors. Regualtive institutionalisation of the triple helix deals predominantly with the role of funding agencies in shaping and structuring the institutional order of the triple helix, given that the normative institutionalisation of the triple helix is grounded in a shared belief of what is appropriate, like, for example, the case for transition to circular economy. The combination of both regulative and normative institutionalization can lead to some level of success for establishing the triple helix system. However, as Cai (2015) argues, it is the build up of cognitive pressures that creates long lasting institutional changes. This is achieved when a critical mass of individuals share the belief that the triple helix approach is the standard way of doing things and act accordingly. The process of 
institutionalisation is iterative in nature and can progress through several cycles before a triple helix system becomes fully institutionalised (Nakwa and Zawdie, 2016).

There is a potential synergy between protected spaces and the triple helix system as outlined in Figure 2. The objective of the protected space is to provide a space for the growth of systemic innovation which requires collaboration between key stakeholders. A protected space may therefore offer the fundamental conditions for a consensus space to evolve that would allow the triple helix system to get to the intra-organizational transformation stage where the triple helix actors engage in trilateral relationships that motivate innovation along agreed trajectories. Protected spaces also provide a clear market orientation for triple helix actors that share the same beliefs on technology innovation. This may allow the knowledge and innovation spaces to better align strategies as well as spark conversation and collaboration between the three actors, thus promoting both normative and cognitive institutionalisation of the triple helix system as identified in Cai (2015), albeit at a niche level (Figure 2 - \#2 \& \#4). A protected space is also an artificial space established by funding agencies and therefore may be used as a mechanism for regulative institutionalisation of the triple helix system, as discussed in Benner \& Sandstrom (2000).

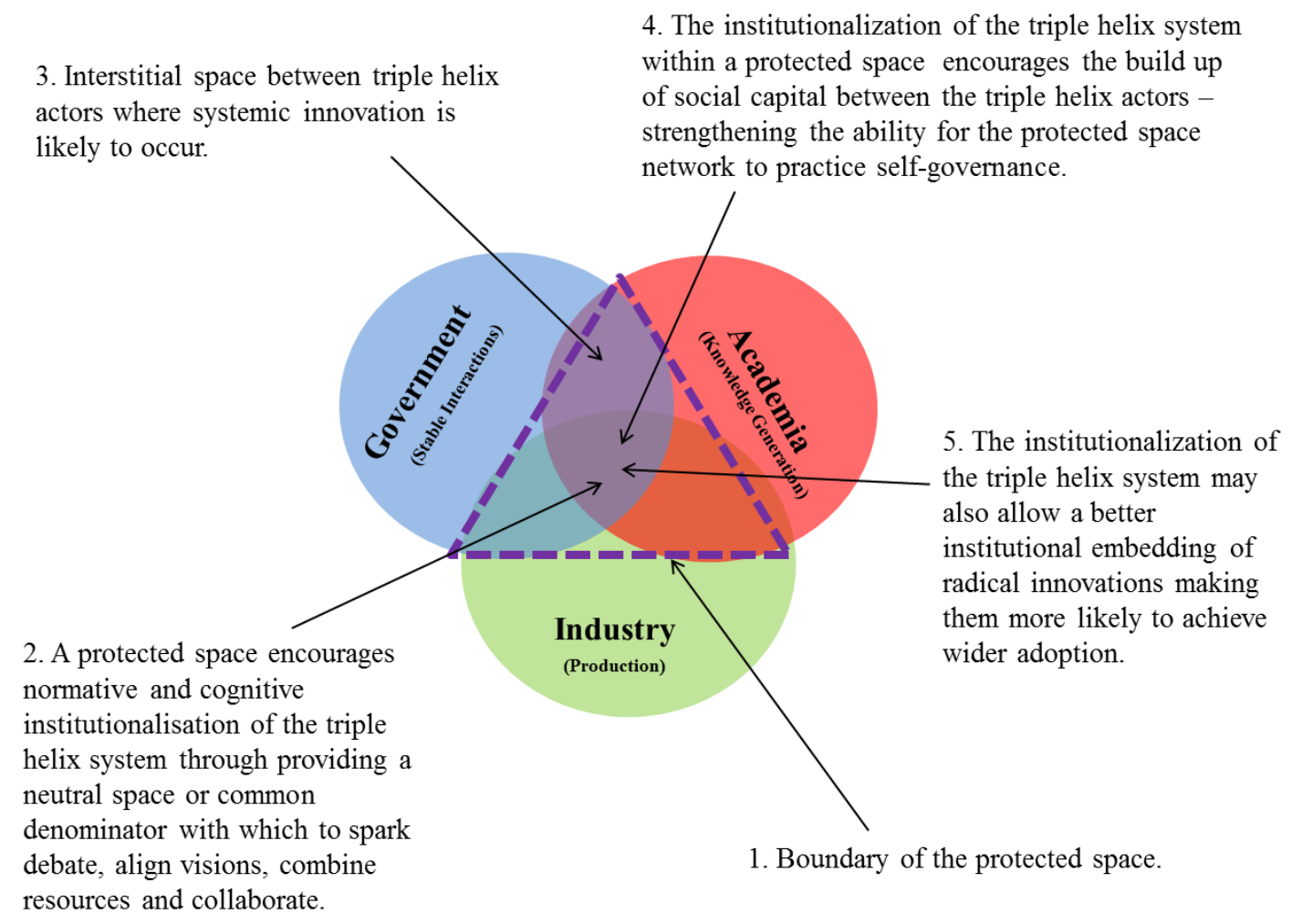

Figure 2: Visualisation of the benefits created through the synergy between protected spaces and the triple helix system

Schot \& Geels (2008) argue that although learning and network development in protected spaces are enhanced by diversity, there is a point at which too much diversity in networks would stunt progress, as it creates uncertainty and a reduced ability to pool resources, and impedes the emergence of a stable set of rules. The formation of a triple helix system within a protected space may offer a balance between achieving diversity between innovation actors and enabling a satisfactory level of coordination by providing a clear network boundary in the form of a protected space (Figure 2 - \#5). 
Implicit in this is the need to break away from the dominant logic of a national and centralised triple helix system towards a more decentralised concept of multiple overlapping triple helix systems. It draws on the argument by Koenig (2012, p.191) that "a basic law of the science of governance is that complexity can only be regulated with matching complexity". The fundamental premise here is that humans are significantly limited in the information they can receive, process and react to. Turnbull $(2002$, p.39) further argues that, due to the complexity and rapid pace of technological development, "it has become physically implausible and economically impractical for central government to monitor and govern the dynamic complexity" of sustainability transitions. The concept of multiple decentralised triple helix systems is therefore a theoretical leap that may offer benefits elsewhere in the field of innovation systems theory. In the context of this paper, the decentralisation of the triple helix system is crucial for leveraging the governance of protected spaces for the development of activities across the economic spectrum aligned to circular economy objectives.

Although protected spaces and the triple helix system appear to demonstrate a potential for symbiosis, the question of governance of a triple helix system within a protected space remains. The following section assesses the potential role of innovation intermediation to address this issue.

\subsection{Innovation System Intermediation}

An innovation intermediary is an organization or a body that plays the role of broker between two or more parties during the innovation process (Howells 2006). The activities of an innovation intermediary range from brokering and mediation of transactions, supplying resources and network building through to accreditation and evaluation of results (Todeva 2013). Innovation intermediation has been demonstrated to be a critical component in the forming, strengthening and empowering of innovation networks (Kivimaa 2014; Howells 2006; Todeva 2013). However, little work has been done yet to explicitly draw a connection between socio-technical transitions and innovation intermediation (Kivimaa 2014).

By adopting the visualisation of a triple helix system within a protected space, Figure 3 demonstrates one of the main limitations of traditional forms of innovation intermediaries whereby they sit in the interstitial space between two of the three triple helix actors such as a university spin out office, or a government agency. By only sitting in the space between two out of the three triple helix actors, such intermediaries, Kivimaa (2014) suggests they are unable to fully understand or influence the wider innovation network dynamics to foster regime change (Figure 3 - \#2). 
4. Triple helix system intermediary would allow for multi-level knowledge transfer (reflexivity) between the protected space and government. This would enable government to more effectively support the wider adoption of innovations created within a protected

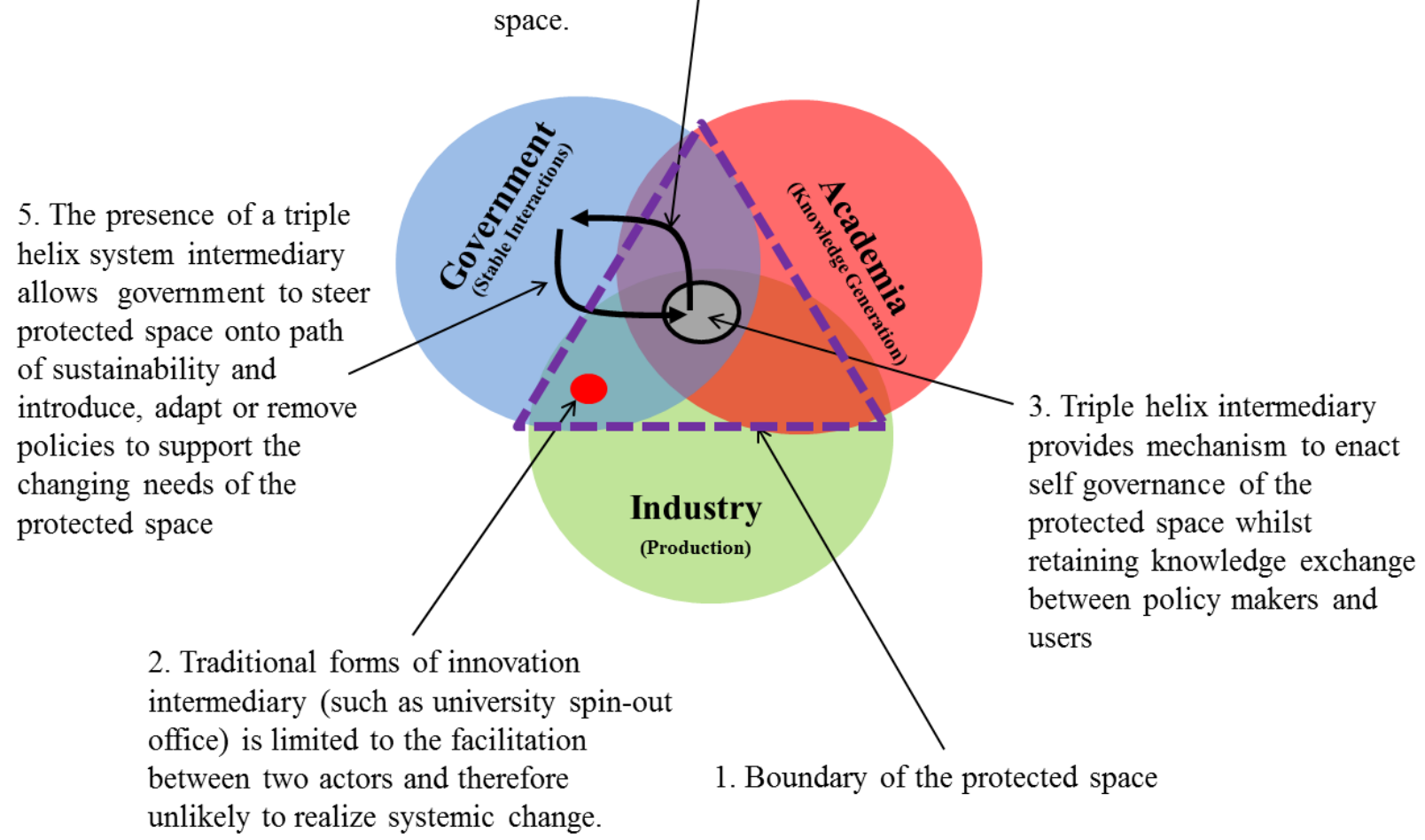

Figure 3: The role of system level triple helix intermediaries in facilitating multi-level knowledge transfer between policy makers and actors as well as facilitating self-governance of the protected space

A number of studies have explored the need for system level intermediaries to support the transition from intra to inter-organizational networks of innovation (Klerkx \& Leeuwis 2009; van Lente et al. 2003; Todeva 2013). As outlined in a study by Kivimaa (2014), a systemic intermediary supports innovation at the higher system level by articulating demand, developing strategy, identifying, aligning and mobilising actors, building consensus, managing complex and long term innovation projects and creating an environment for learning by doing and using. Kivimaa (2014) concludes that the "existence of system intermediaries is likely to be crucial to achieving regime destabilisation".

If a triple helix system were to form within a protected space, the triple helix actors need to progress from intra to inter-organizational transformation. In other words, triple helix actors have to evolve from just assuming a role of the other triple helix actor as a secondary activity to a closer form of trilateral cooperation (Cai 2015; Etzkowitz 2008). What is needed, therefore, is a triple helix system intermediary, which is jointly governed by all three triple helix actors within the protected space. Such an intermediary would offer a mechanism with which trilateral cooperation and concensus can evolve between the three triple helix actors (Figure 3 \#3).

With regard to managing niches, Weber et al. (1999) and Heidenreich et al. (2016) identified that a crucial factor for the success of an innovation network is routed in the presence of a network manager who encourages and facilitates innovation and provides dynamic management. Kemp et al. (1998; p.189) also propose that "many [niche] projects have a socalled 'project bureau' that is formally in charge of project management". Therefore, a triple 
helix system intermediary may not only enable the build up of social capital between the triple helix actors, but may also be utilised as an operational tool for building self governance capacity of protected space networks by assuming the role of niche project manager.

Moreover, a triple helix system intermediary that is co-governed by all three actors may enable more open and effective knowledge exchange between actors involved in the protected space and policy makers (Figure 3 - \#4 \& \#5).

A triple helix system intermediary would thus be employed as a vehicle to (i) operationalize the formation of a triple helix consensus within a protected space; (ii) enable self-governance within the protected space; and (iii) retain knolwedge flow between decision makers within the protected space and policy makers in the domain of central government. But how, it may be asked, does this connect with the problematics of transition to circular economy? It is to this question that the following section is addressed.

\section{Triple Helix-leveraged transition to circular economy}

\subsection{The triple helix consensus against prevailing socio-technical regimes}

Transition to circular economy involves systems changes in which deeply embedded path dependencies and lock-ins in the socio-technical regimes that underpin the traditional linear 'make, use, dispose' economic model are disrupted. Thus in the transition process, major shifts would be expected to occur in technological trajectories as a result of innovation, and also in market trajectories as a result of changing socio-economic trends. These trajectories would also be expected to align in a systemic framework to ensure that the use of resources across the economic spectrum increasingly leads to a 'zero waste' situation (Webster 2015).

The argument in this paper is that transition to circular economy is best approached through the identification and prioritization of strategic sectors that align with circular economy principles and the subsequent creation of 'protected spaces' with a system of governance that would help enhance the disruption of socio-technical regimes associated with the linear model of economic activities.

The application of strategic niche management to protected spaces, while providing the necessary condition for niche innovation, lacks the consensus, network reflexivity and social capital base to be able to disrupt incumbent socio-technical regimes and provide mechanisms to impact social functions, and activities in wealth creation and organised knowledge production, thus paving the way for a circular economy transition. SNM is essentially a topdown governance system which invokes network tension for lack of reflexivity. This would make it restrictive in terms of its contribution to enhancing innovation and possibilities for transition to circular economy.

The task of SNM is likely to increase in complexity as the circular economy transition requires protected spaces with much wider network boundaries to promote the cross sectoral uptake of disruptive platform technologies such as industrial biotechnology.

This problem is likely to be mitigated when SNM is applied in the context of the triple helix system, as this would enhance the consensus, network reflexivity and social capital base. The issue of triple helix-leveraged transition to circular economy, however, raises questions about how the 'consensus space' translates into a 'transition space'. This can be explained in terms of the engagement of policy with all triple helix players in the 'consensus space'. 
First, the triple helix system can be decentralised, so that protected spaces can be expected to evolve not only along their respective trajectories, but also horizontally learning from the experiences of other protected spaces and identifying opportunities that would enhance their contribution to the making of the circular economy. At the heart of the 'horizontal learning' process is the development of networks that increase the ability of protected spaces to selfgovern, whilst accumulating systems-oriented knowledge that would equip them for participation in circular economy activities. Conceptually, this melding of the triple helix system with the management of protected spaces can be construed as a decentralised 'hub and spoke' model of triple helix innovation and governance aimed at transition to circular economy. In this model, the circular economy strategy of governments constitutes the hub, and the range of protected spaces that address key circular economy challenge areas, the spokes. The interconnectedness of the players in the model and the commonality of the overarching challenges the model seeks to address would define the pathway to a circular economy end.

Second, triple helix provides a 'consensus space'. This space allows for the emergence of a wide range of possibilities, challenging all players involved in social functions, wealth creation, organised knowledge production and the regulation and control of activities to select and shape technological trajectories recursively over time. This would help remove path-dependency lock-ins that otherwise inhibit the transition to circular economy. The triple helix consensus space, which is brokered by network intermediaries, provides a stabilising bridge between supply push and demand pull forces and top-down and bottom-up pressures on the choice environments, including the selection mechanism of the market; the stabilisation mechanism of policy; and the globalisation mechanism of knowledge generation and knowledge exchange (Leydesdorff and Zawdie 2010).

Third, when it comes to transition to circular economy, the role of policy is not so much to stabilise as to create the conditions for innovations to occur, so that the path dependency lockins of existing socio-technical regimes become no longer attractive in the light of the conditions that constitute a circular economy trajectory. In the circumstances, firms engaged in wealth creation would opt for technological regimes based on a 'closed loop' or 'cradle-to-cradle' approach to production or what Walter Stahel refers to as 'performance economy' (Stahel 2010). When major changes in policy occur in a sustained manner, they would also create the conditions for the path dependency lock-ins in the incumbent socio-technical regimes to give way to a new generation of lock-ins (Dosi 1982) with circular economy appeal. Thus, for example, when policy seeks to foresee and prepare the economy for changing landscape pressures such as climate change, resource depletion and increasing market volatility, it enhances the consensus space for transition to a circular economy.

The above points can be graphically represented as in Figure 4, where it is shown how topdown and bottom-up activities of the triple helix actors can be synchronised to produce a triple helix consensus space from where the circular economy trajectory can be defined in terms of appropriate knowledge and market systems and sustained through innovation (Webster 2015).

A circular economy matrix can be defined in terms of technology/knowledge and market dimensions. In the model set out in Figure 4, a circular economy-oriented knowledge system is conceived to involve the generation and diffusion of knowledge within a triple helix framework. The knowledge being generated and diffused relate to scientific, technological, production, market, logistics and design knowledge that is aligned with a particular inner loop activity, such as biorefinery or remanufacturing. The generation and diffusion of knowledge is thus driven by specific production and market imperatives, catering for a circular economy end. 
A circular economy-oriented market system involves relations corresponding to intermediate as well as final demand. Intermediate demand derives from a constellation of firms which operate within the value chains associated with particular inner loop activities, such as biorefinery. These firms use circular economy-oriented knowledge to undertake inner loop activities, such as, for example, feedstock production, processing and handling or downstream users of bio-refined feedstock. They also engage in articulating demand for inner loop activities to the rest of the value chain. Final demand, on the other hand, derives from the wider end-use or consumer market, which, in a circular economy context, would be expected to express preference for product designs that contribute to the saving of energy and material resources across inner loop activities.

In a circular economy, knowledge and market systems complement each other, thus defining the nexus of knowledge generation, knowledge use/application and economies of material and energy resources in production that is well aligned to prevailing market profiles. Policy plays a major role in shaping the market and knowledge profiles; but the role of governing the transition to a circular economy by supporting the growth of multiple niche inner loop activities could be complex as it involves providing for the coordination of and collaboration between circular economy-oriented knowledge and market systems that are specific to each inner loop, while at the same time guiding specific inner loop activities to constructively develop in alignment with multiple other inner loops.

Figure 4 sets out firms in protected spaces according to the extent of their awareness of and engagement with knowledge and market systems that constitute transition to circular economy ${ }^{1}$. The cluster of firms in space A are poorly positioned for transition as the extent of their awareness of and engagement with circular economy-oriented knowledge and market systems is low. Firms in B and C are relatively more networked than those in A. Those in B are likely to engage in knowledge exchange processes. Yet they have low levels of knowledge exploitation as they may be either unaware or else are uninterested in new markets because of associated risks. Those in $\mathrm{C}$ have developed their market networks to exploit their knowledge deriving from in-house $R \& D$ initiatives, but rarely engage in knowledge sharing and knowledge exchange exercises.

Triple helix consensus is achieved in space D, where the extent of firms' awareness of and engagement with circular economy-oriented knowledge and market systems is high. In this respect, policy would aim to provide the overarching strategic framework defining the direction along which the economy would be expected to evolve, while at the same time developing appropriate networks for knowledge systems and market systems to develop based on the institutionalisation of the circular economy, and for triple helix actors to freely interact regularly, exchanging knowledge and exploring and exploiting opportunities.

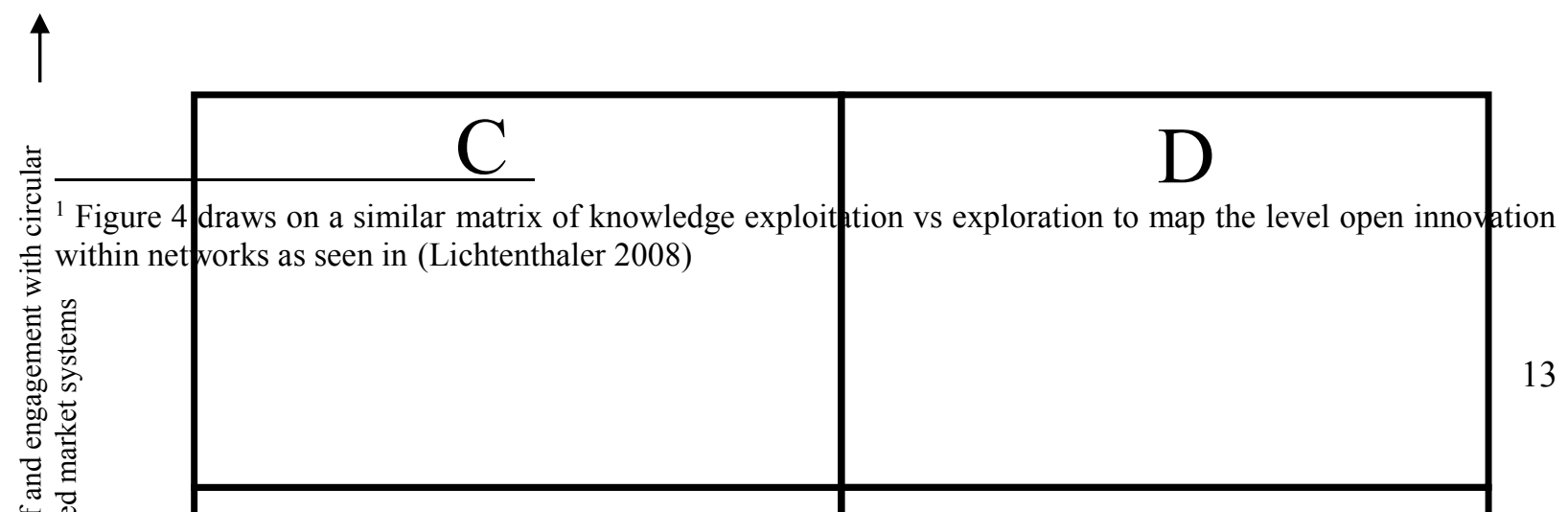




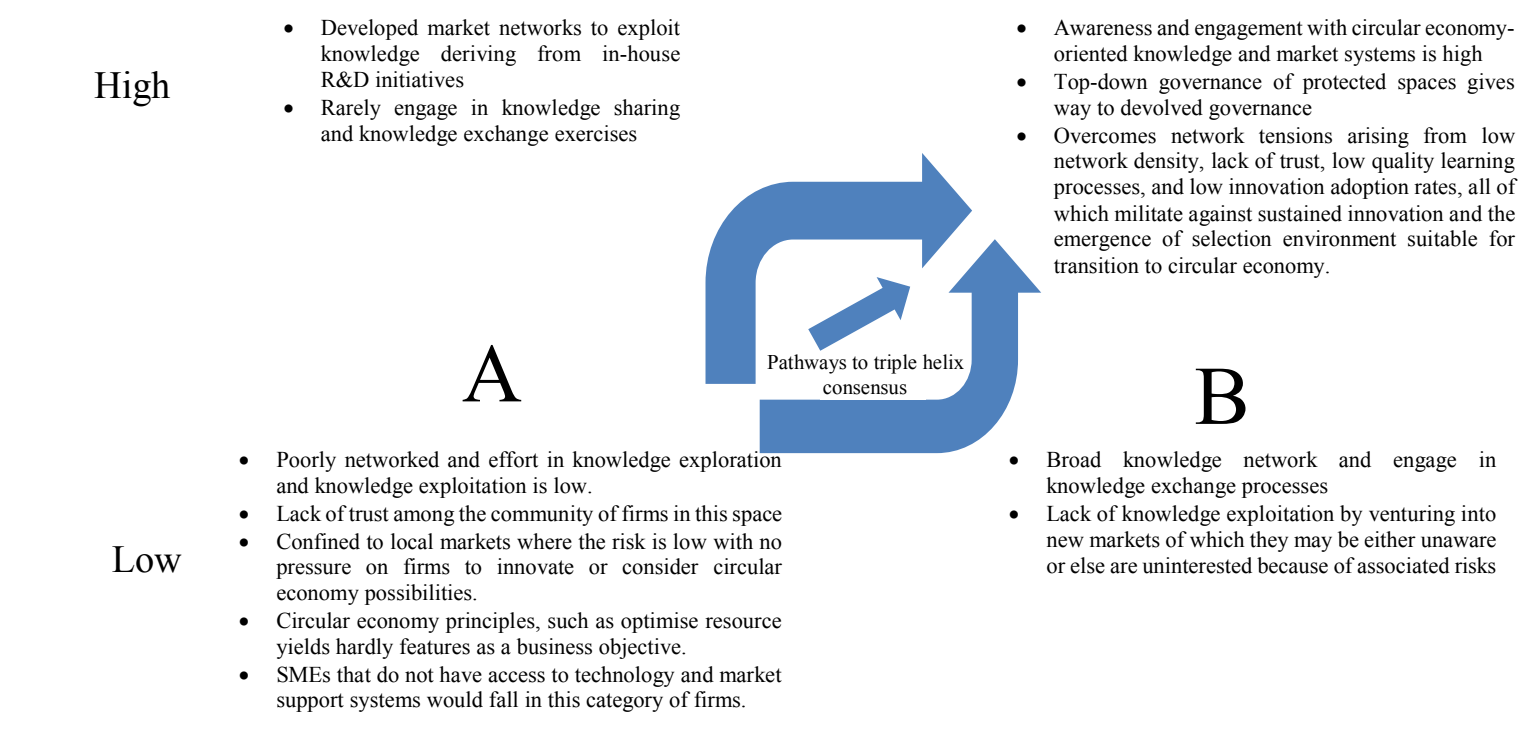

Low High

Extent of firms' awareness of and engagement with circular economy-oriented knowledge systems

Figure 4: The role of policy in fostering an environment that allows for high firm awareness and engagement with circular economy knowledge and market systems across all sectors of the economy

Most of the firms in protected spaces would be expected to be found spread across A, B and C. This means that there are three pathways to triple helix consensus: from A to D which poses a daunting challenge for policy as firms in A are given to low awareness about and engagement with circular economy-oriented knowledge and market systems; from B to D, where the task of policy is to promote awareness of and engagement with circular economy-oriented market systems among firms in B through the role of intermediary organisations and the use of tax regimes that bear on relative factor prices and product prices; and from $\mathrm{C}$ to $\mathrm{D}$, where policy would be expected to promote circular economy-oriented knowledge systems through training and $\mathrm{R} \& \mathrm{D}$ support to firms in $\mathrm{C}$.

It is apparent from the discussion above that policy plays a crucial role in championing the transition to circular economy. It does this by creating protected spaces and leveraging the strategic niche management of these protected spaces and by providing the conditions for triple helix consensus which provides the selection environment that would allow lock-ins in favour of circular economy trajectories. However, the fact that circular economy is more of a desired policy objective yet to be achieved, as is the case in many countries, suggests that policy has yet to surmount social, cultural, economic and technological barriers to play the handmaiden of transition to circular economy. The significance of the challenge policy has to contend with to provide the conditions for transition to circular economy can be appreciated in the light of the Scottish experience, which is briefly discussed below.

\subsection{The Scottish experiment in triple helix-leveraged transition to circular economy}

The information used in this section is drawn from a mixture of primary and secondary sources, which respectively involved expert interviews/dialogues and a survey of relevant literature and 
archival data that were collected to provide the empirical basis for the doctoral thesis of the lead author of this paper ${ }^{2}$. As noted earlier, the aim of this paper is not so much to engage in detailed empirical analysis as to provide a heuristic framework for a triple helix-based transition to circular economy in industrially developed countries by invoking a narrative of the Scottish initiative to provide the basis for further empirical work on the challenges of transition to circular economy. A descriptive account of the Scottish experience to date with respect to the relationship between triple helix and transition to circular economy is therefore presented below to help shed some light not only on the attractiveness of the circular economy issue in terms of its relevance to a sustainable future, but also on the daunting nature of the challenge the proposed transition involves.

In March, 2016, the Scottish Government published a national circular economy strategy titled 'Making Things Last: A Circular Economy Strategy for Scotland' (Scottish Government 2016). Alongside the Netherlands, Denmark and China the strategy proposes some of the most ambitious circular economy targets globally, particularly around the issues of reducing domestic waste to landfill and reducing food waste.

The strategy outlines the importance of growing lead circular economy markets in particular, re-manufacturing and industrial biotechnology. There is clear understanding that innovation lies at the heart of growing these lead markets. Accordingly, a strategic niche management model has been adopted to encourage the growth of radical innovation within 'protected spaces' through the provision of access to capital and the formation of two triple helix system intermediaries, the Industrial Biotechnology Innovation Centre (IBioIC) and the Scottish Institute for Re-manufacturing (SIR). The triple helix approach is most clearly observed within the governance structure of these intermediaries.

Scotland's transition to a circular economy offers an ideal case study to assess the strengths, weaknesses, opportunities and threats policymakers would encounter when attempting to grow lead markets in the transition process. The Scottish case relating to IBioIC and SIR also sheds light on the development of a novel governance framework based on a synergy of the strategic niche management of protected spaces, the triple helix system and innovation/knowledge intermediaries. The role of IBioIC and SIR is to act as self-governance mechanisms for the protected spaces as well as facilitating knowledge exchange between government, academia and industry.

In the space of two years, IBioIC has already brokered 15 industry-university exemplar projects and built a strong and diverse network between 60 firms and 11 universities (IBioIC 2016). The scale of this ambition represents the level of optimism in the triple helix approach being employed by IBioIC to support the governance of a protected space.

Similarly, it is apparent from the experience of SIR as a system intermediary that the application of strategic niche management in the context of the triple helix system could enhance the role of protected spaces as an effective platform for transition to circular economy. In its first year, SIR brokered 12 university-industry collaborative projects and has built a membership network of 41 companies and five academic institutes. As well as facilitating the self governance of the protected space, SIR also plays a key role in promoting knowledge exchange from the remanufacturing protected space network to wider government

\footnotetext{
${ }^{2}$ Work by Jack Barrie on thesis entitled "The triple helix governance framework for transition to circular economy with particular reference to the bio-industry and remanufacturing sectors in Scotland" currently in progress.
} 
sustainability and economic initiatives such as the Scottish Circular Economy Network, the Manufacturing Action Plan and the Circular Economy Investment Fund and Service.

The two cases that are promoted to spearhead transition to circular economy in Scotland show the enthusiasm of policy to see the national circular economy strategy implemented. This enthusiasm is also reflected in the establishment of eight innovation centres ${ }^{3}$, although it is not clear to what extent the launching of the innovation centres was driven by the specific objective of transition to circular economy. Nor is it clear yet how these innovation centres have set themselves to address the question of transition to circular economy. What is, however, significant in the Scottish experience is the creation of protected spaces and the promotion of the triple helix framework to leverage the strategic niche management of the protected spaces as policy mechanisms for transition to circular economy. There is as yet no evidence of a fully evolved triple helix consensus space to mitigate network tensions and allow self-governance of the protected spaces; nor of any material shift from the traditional 'take-make-dispose' linear economic model to the systemic 'cradle-to-cradle' or 'closed loop' or 'zero waste' circular economy model. This is perhaps not surprising considering that the protected spaces have not had much time yet to evolve in the direction of circular economy.

However, questions arise about the configuration of firms in the protected spaces - at least where IBioIC and SIR are playing the role of triple helix intermediary organisations - regarding the extent of their awareness of and engagement with circular economy-oriented knowledge and market systems, as discussed in Figure 4. There is need for research to shed light on the extent to which individual firms are networked within their respective industries and across sectors to explore and exploit knowledge in the context of circular economy transition; and also on the extent to which they would trade-off short-term profitability and business turnover objectives against the pursuit of long-term circular economy objectives. The scope for transition to circular economy in Scotland, as indeed elsewhere, can be attributed partly to the prevalence of the short-term profitability objective as a driver of business behaviour; partly to shortfalls in the development of knowledge and market networks and hence in the supply of social capital; and partly to the lack of trust among firms and also between firms, who use knowledge to create wealth, and other triple helix players, who produce knowledge as well as those who regulate and control its production and use.

It can be argued that the pursuit of policy to promote awareness of a 'zero-waste' or circular economy culture through intermediary organisations like IBioIC and SIR is likely to strengthen the basis for a triple helix consensus to emerge across protected spaces, thus enabling the choice of growth trajectories aligned to circular economy objectives. For now, however, the jury is out while research explores evidence about the viability of transition to circular economy in terms of cost-benefit analysis.

\section{Conclusion}

This paper has attempted to shed some light on the use of 'protected spaces' as a strategy for transitioning to circular economy. The effectiveness of protected spaces in providing the conditions for the development of circular economy systems would in large measure depend on the nature of the strategic niche management underpinning the governance of protected

\footnotetext{
${ }^{3}$ The eight innovation centres include: Centre for Sensor and Imaging Systems, Construction Scotland Innovation Centre, Digital Health and Care Institute, Industrial Biotechnology Innovation Centre, Oil and Gas Innovation Centre, Scottish Aquaculture Innovation Centre, Stratified Medicine and The Data Lab.
} 
spaces and particularly the extent to which SNM allows reflexivity in the governance system through the active participation of the triple helix players and system intermediaries to promote knowledge generation and knowledge use in-line with circular economy principles. The transformation of a 'protected space' into a triple helix 'consensus space' upon the confluence of the 'knowledge space' (pitched by academia) and 'innovation space' (pitched by industry) provides the social, cultural, economic, technological and environmental conditions for sustainable innovation and the subsequent emergence of a circular economy.

The paper has also discussed the strengths and limitations of three separate innovation policy tools that are concurrently administered to stimulate systemic innovation and pave the way for transition to circular economy via the triple helix consensus space. Strategic niche management supports the formation and protection of a network of innovators, yet it lacks the governance mechanism that simultaneously encourages self-governance of the protected space network and the efficient exchange of knowledge among the plethora of network of players and policy makers. The triple helix approach would specifically define the key network players as knowledge creators, knowledge users and enablers of knowledge generation and knowledge use. However, for greater knowledge exchange and consensus formation between key innovation stakeholders within protected spaces, systems intermediaries are sought to ensure self-governance of the protected spaces and to strengthen the rate of knowledge flow from the network to policy makers. The role of system intermediaries can, however, be constrained by government policy strictures.

The integration of the triple helix concept with SNM to provide the basis of a strategy for transition to circular economy through the creation of protected spaces given to systems-based reflexivity of governance is a new area of research, and so there is knowledge gap yet to be filled in this respect. The challenge for research is to show not only how reflexivity and resilience can be built into the governance of protected spaces, but also how protected spaces can be made to induce innovative activities that are consistent with circular economy imperatives. It can be argued that transition to circular economy might require the simultaneous establishment and management of multiple heterogeneous protected spaces within the framework of triple helix consensus discussed in this paper. This paper has sought to show that centralised and top-down approaches to the governance of protected spaces, which pre-empt the emergence of the triple helix consensus space, are unlikely to be able to cope with the complexity of transition to circular economy.

Although this paper has raised important issues of policy and strategy for circular economy transition, it is not without limitations. The governance framework proposed in the paper is based on a review of the relevant literature and in the light of the Scottish experience. However, the governance framework has yet be put to a robust empirical test either through observation of an existing case of a triple helix system intermediary forming within a protected space or through a more action-based approach. It was also specifically developed in the light of the experience of high-tech sectors in regions that, despite having strong scientific knowledge production capabilities, suffer from the inability to commercialise that knowledge. Although the proposed governance framework considers knowledge flow between the protected spaces and government, further refinement of the model is required to understand the dynamics arising through lateral knowledge transfer between protected spaces. Further research is also required to analytically relate the triple helix system and the Scottish context to knowledge and market systems. 


\section{Acknowledgements}

We would like to thank Ewan Mearns, Senior Manager in the Strategy and Economics Team at Scottish Enterprise and Robert Tooze from Sasol for reviewing the paper in depth and providing insights into current circular economy developments in Scotland. We would also like to thank the Andrés Valderrama and Professor Ulrik Jørgensen for running the Theories of Sustainable Transitions course at Aalborg University through which we received invaluable feedback on the paper.

Funding: This work was supported by the UK Engineering and Physical Sciences Research Council (EPSRC).

\section{References}

Benner, M. \& Sandstrom, U., 2000. Institutionalizing the triple helix : research funding and norms in the academic system. Research Policy, 29, pp.291-301.

Boon, W.P.C., Moors, E.H.M. \& Meijer, A.J., 2014. Exploring dynamics and strategies of niche protection. Research Policy, 43(4), pp.792-803. Available at: http://dx.doi.org/10.1016/j.respol.2014.01.005.

Boraschi, D. et al., 2010. Ageing and immunity. Vaccine, 28(21), pp.3627-3631. Available at: http://linkinghub.elsevier.com/retrieve/pii/S0264410X10004111.

Cai, Y., 2015. What contextual factors shape "innovation in innovation"? Integration of insights from the Triple Helix and the institutional logics perspective. Social Science Information, 54(3), pp.299-326. Available at: http://ssi.sagepub.com.proxy.library.uu.nl/content/early/2015/05/15/0539018415583527. full.

Caniëls, M.C.J. \& Romijn, H. a, 2008. Actor networks in Stategic Niche Management: Insights from social network theory. Futures, 40, pp.613-629.

Cooke, P. \& Wills, D., 1999. Small Firms, Social Capital and the Enhancement of Business Performance Through Innovation Programmes. Small Business Economics, 13, pp.219234.

Cossio, M.L.T. et al., 2015. Circular Economy: A critical Literature Review of Concepts, Available at:

http://www.ciraig.org/pdf/CIRAIG_Circular_Economy_Literature_Review_Oct2015.pd f.

Ellen MacArthur Foundation, 2015. Delivering the Circular Economy: A Toolkit for Policymakers, Available at: https://www.ellenmacarthurfoundation.org/publications.

Etzkowitz, H., 2003. Innovation in Innovation: The Triple Helix of University-IndustryGovernment Relations. Social Science Information, 42(3), pp.293-337. Available at: http://ssi.sagepub.com/cgi/doi/10.1177/05390184030423002.

Etzkowitz, H., 2002. The Triple Helix of University - Industry - Government: Implications for Policy and Evaluation. Working Paper, p.18.

Etzkowitz, H., 2011. The Triple Helix: University-industry-government innovation in action. 
Papers in Regional Science, 90(2), pp.441-442. Available at: http://doi.wiley.com/10.1111/j.1435-5957.2011.00357.x.

Etzkowitz, H., 2008. The Triple Helix: University-industry-government innovation in action., Routledge (London and New York).

Etzkowitz, H. \& Leydesdorff, L., 2000. The dynamics of innovation: from National Systems and "Mode 2" to a Triple Helix of university-industry-government relations. Research Policy, 29(2), pp.109-123.

Etzkowitz, H. \& Leydesdorff, L., 1995. The Triple Helix---University-Industry-Government Relations: A Laboratory For Knowledge Based Economic Development. EASST Review, 14(1), pp.14-19.

Farinha, L., Ferreira, J. \& Gouveia, B., 2016. Networks of Innovation and Competitiveness: A Triple Helix Case Study. Journal of the Knowledge Economy, 7(1), pp.259-275. Available at: http://link.springer.com/10.1007/s13132-014-0218-3.

Food and Agriculture Organization, 2010. Global Forest Resources Assessment 2010 Main Report, Rome. Available at: http://www.fao.org/docrep/013/i1757e/i1757e.pdf.

Geels, F.W., 2002. Technological transitions as evolutionary reconfiguration processes: a multi-level perspective and a case-study. Research Policy, 31(8-9), pp.1257-1274. Available at: http://dx.doi.org/10.1016/S0048-7333(02)00062-8.

Heidenreich, S., Landsperger, J. \& Spieth, P., 2016. Are Innovation Networks in Need of a Conductor? Examining the Contribution of Network Managers in Low and High Complexity Settings. Long Range Planning, 49(1), pp.55-71. Available at: http://dx.doi.org/10.1016/j.lrp.2014.03.003.

Howells, J., 2006. Intermediation and the role of intermediaries in innovation. Research Policy, 35(5), pp.715-728. Available at:

http://linkinghub.elsevier.com/retrieve/pii/S0048733306000497.

IBioIC, 2016. IBioIC Annual Report 2015, Available at: https://issuu.com/ashleyjackson4/docs/ibioic_annual_report_2014/1.

Kemp, R., Schot, J. \& Hoogma, R., 1998. Regime shifts to sustainability through processes of niche formation: The approach of strategic niche management. Technology Analysis \& Strategic Management, 10(2), pp.175-198. Available at: http://www.tandfonline.com/doi/abs/10.1080/09537329808524310.

Kivimaa, P., 2014. Government-affiliated intermediary organisations as actors in systemlevel transitions. Research Policy, 43(8), pp.1370-1380. Available at: http://dx.doi.org/10.1016/j.respol.2014.02.007.

Klerkx, L. \& Leeuwis, C., 2009. Establishment and embedding of innovation brokers at different innovation system levels: Insights from the Dutch agricultural sector. Technological Forecasting and Social Change, 76(6), pp.849-860. Available at: http://dx.doi.org/10.1016/j.techfore.2008.10.001.

Koenig, D., 2012. Governance Reimagined: Organizational Design, Risk, and Value Creation. Hoboken: John Wiley \& Sons 
van Lente, H. et al., 2003. Roles of Systemic Intermediaries in Transition Processes. International Journal of Innovation Management, 07(03), pp.247-279. Available at: http://www.worldscientific.com/doi/abs/10.1142/S1363919603000817.

Leydesdorff, L., 2012. The Triple Helix, Quadruple Helix, ..., and an N-Tuple of Helices: Explanatory Models for Analyzing the Knowledge-Based Economy? Journal of the Knowledge Economy, 3(1), pp.25-35. Available at: http://link.springer.com/10.1007/s13132-011-0049-4.

Leydesdorff, L. and Zawdie, G., 2010.The triple helix perspective of innovation systems. Technology Analysis \& Strategic Management, 22(7), pp. 789-804.

Lichtenthaler, U., 2008. Open Innovation in Practice: An Analysis of Strategic Approaches to Technology Transactions. IEEE Transactions on Engineering Management, 55(1), pp.148-157. Available at: http://ieeexplore.ieee.org/document/4429843/.

Markard, J., Raven, R. \& Truffer, B., 2012. Sustainability transitions: An emerging field of research and its prospects. Research Policy, 41(6), pp.955-967. Available at: http://dx.doi.org/10.1016/j.respol.2012.02.013.

Markard, J. \& Truffer, B., 2006. Innovation processes in large technical systems: Market liberalization as a driver for radical change? Research Policy, 35(5), pp.609-625. Available at: http://linkinghub.elsevier.com/retrieve/pii/S0048733306000606.

Mlecnik, E., 2014. Which factors determine the success of strategic niche developments?: Reflections from the emergence of a passive house network. Construction Innovation: Information, Process, Management, 14(1), pp.36-51. Available at: http://www.emeraldinsight.com/10.1108/CI-01-2012-0007.

Nakwa, K. and Zawdie, G., 2015. Structural holes, knowledge intermediaries and evolution of the triple helix system with reference to the hard disk drive industry in Thailand. International Journal of Technology Management and Sustainable Development, 14(1), pp. 29-47.

Nakwa, K. and Zawdie, G., 2016. The 'third mission' and 'triple helix mission' of universities as evolutionary processes in the development of the network of knowledge production: Reflections on SME experiences in Thailand. Science and Public Policy, 43(5), pp. 622-629.

Nill, J. \& Kemp, R., 2009. Evolutionary approaches for sustainable innovation policies: From niche to paradigm? Research Policy, 38(4), pp.668-680. Available at: http://linkinghub.elsevier.com/retrieve/pii/S004873330900016X.

Nilsson, M., Hillman, K. \& Magnusson, T., 2012. How do we govern sustainable innovations? Mapping patterns of governance for biofuels and hybrid-electric vehicle technologies. Environmental Innovation and Societal Transitions, 3, pp.50-66. Available at: http://dx.doi.org/10.1016/j.eist.2012.04.002.

Ranga, M. \& Etzkowitz, H., 2013. Triple Helix systems: an analytical framework for innovation policy and practice in the Knowledge Society. Industry and Higher Education, 27(4), pp.237-262. Available at: http://openurl.ingenta.com/content/xref?genre=article\&issn $=0950$ $4222 \&$ volume $=27 \&$ issue $=4 \&$ spage $=237$. 
Raven, R., 2005. Strategic Niche Management for Biomass Strategic Niche Management for Biomass. Technische Universiteit Eindhoven. Available at: http://w3.tm.tue.nl/fileadmin/tm/TDO/Rob_Raven.pdf.

Raven, R.P.J.M., 2006. Towards alternative trajectories? Reconfigurations in the Dutch electricity regime. Research Policy, 35(4), pp.581-595. Available at: http://linkinghub.elsevier.com/retrieve/pii/S0048733306000382.

Rip, A. \& Kemp, R., 1998. Technological Change. In S. Rayner \& L. Malone, eds. Human Choice and Climate Change. Washington D.C.: Battelle Press, pp. 327-399.

Rosenberg, N., 1976. Perspectives on Technology, Cambridge: Cambridge University Press. Available at: http://ebooks.cambridge.org/ref/id/CBO9780511561313.

Schot, J. \& Geels, F.W., 2008. Strategic niche management and sustainable innovation journeys: theory, findings, research agenda, and policy. Technology Analysis \& Strategic Management, 20(5), pp.537-554. Available at: http://dx.doi.org/10.1080/09537320802292651.

Scottish Government, 2016. A Circular Economy Strategy for Scotland, Available at: http://www.gov.scot/Resource/0049/00494471.pdf.

Shove, E. \& Walker, G., 2007. CAUTION! Transitions ahead: politics, practice, and sustainable transition management. Environment and Planning A, 39(4), pp.763-770. Available at: http://epn.sagepub.com/lookup/doi/10.1068/a39310.

Smith, A., 2004. Alternative Technology Niches and Sustainable Development. Innovation: Management, Policy \& Practice, 6(2), pp.220-235. Available at: http://pubs.econtentmanagement.com/doi/abs/10.5172/impp.2004.6.2.220.

Smith, A. \& Raven, R., 2012. What is protective space? Reconsidering niches in transitions to sustainability. Research Policy, 41(6), pp.1025-1036. Available at: http://dx.doi.org/10.1016/j.respol.2011.12.012.

Stahel, W., (2010) The Performance Economy, Second Edition, London: PalgraveMacMillan

Todeva, E., 2013. Governance of innovation and intermediation in Triple Helix interactions. Industry and Higher Education, 27(4), pp.263-278. Available at: $\mathrm{http}: / /$ openurl.ingenta.com/content/xref?genre=article\&issn $=0950$ $4222 \&$ volume $=27 \&$ issue $=4 \&$ spage $=263$.

Turnbull, S., 2002. A New Way to Govern, London: New Economics Foundation.

Ulmanen, J.H., Verbong, G.P.J. \& Raven, R.P.J.M., 2009. Biofuel developments in Sweden and the Netherlands. Renewable and Sustainable Energy Reviews, 13(6-7), pp.14061417. Available at: http://linkinghub.elsevier.com/retrieve/pii/S1364032108001718.

Verbong, G., Geels, F.W. \& Raven, R., 2008. Multi-niche analysis of dynamics and policies in Dutch renewable energy innovation journeys (1970-2006): hype-cycles, closed networks and technology-focused learning. Technology Analysis \& Strategic Management, 20(5), pp.555-573. Available at: http://www.tandfonline.com/doi/abs/10.1080/09537320802292719. 
Verhees, B. et al., 2015. The role of policy in shielding, nurturing and enabling offshore wind in The Netherlands (1973-2013). Renewable and Sustainable Energy Reviews, 47, pp.816-829. Available at:

http://linkinghub.elsevier.com/retrieve/pii/S1364032115001240.

Voß, J.-P. \& Kemp, R., 2005. Reflexive Governance for Sustainable Development Incorporating feedback in social problem solving. In Special session on Transition management. Lisbon, pp. 1-31. Available at:

http://www.orobievive.net/conoscere/politiche_sostenibilita.pdf.

Weber, M. et al., 1999. Experimenting with Sustainable Transport Innovations. A workbook for Strategic Niche Management, Available at: http://purl.tue.nl/573400255309879.

Webster, K., 2015. The Circular Economy: A Wealth of Flows. UK: EMF Publishing.

Webster, K., Blerot, J. and Johnson, C. (eds.), 2013. A New Dynamic: Effective Business in a Circular Economy. UK: EMF Publishing.

Webster, K., Blerot, J. and Johnson, C. (eds.), 2016. A New Dynamic 2: Effective Systems in a Circular Economy. UK: EMF Publishing.

de Wildt-Liesveld, R., Bunders, J.F.G. \& Regeer, B.J., 2015. Governance strategies to enhance the adaptive capacity of niche experiments. Environmental Innovation and Societal Transitions, 16, pp.154-172. Available at:

http://www.sciencedirect.com/science/article/pii/S2210422415000283.

WWF, 2015. Living Blue Planet Report, Available at:

http://assets.wwf.org.uk/downloads/living_blue_planet_report_2015.pdf?_ga=1.259860 873.2024073479.1442408269.

WWF, 2014. Living Planet Report 2014, Available at:

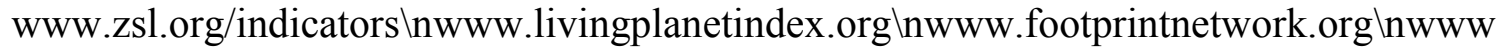
.waterfootprint.org.

Yokakul, N. \& Zawdie, G., 2009. The Role of Triple Helix for Promoting Social Capital, Industrial Technology and Innovation in the SME Sector in Thailand. Science Technology \& Society, 14(1), pp.93-117. 